\title{
Attitudes do matter: The role of attitudes and personality in DUI offenders
}

\author{
Montsant Jornet-Giberta ${ }^{\mathrm{a}}$, David Gallardo-Pujol a,b,*, Carlos Suso ${ }^{\mathrm{a}}$, Antonio Andrés-Pueyo ${ }^{\mathrm{a}, \mathrm{b}}$ \\ a Dept. of Personality, Universitat de Barcelona, Spain \\ ${ }^{\mathrm{b}}$ Institute for Brain, Cognition and Behavior (IR3C), Universitat de Barcelona, Spain
}

\section{A R T I C L E I N F O}

\section{Article history:}

Received 12 December 2011

Received in revised form 24 April 2012

Accepted 21 May 2012

\section{Keywords:}

DUI

Personality

Attitudes

Neuroticism

Conscientiousness

Traffic offending

\begin{abstract}
A B S T R A C T
Several studies have related personality variables with antisocial behavior. Among antisocial behaviors, driving under the influence (DUI) has received growing attention in recent years, particularly in relation to the role of personality. However, it has been shown that personality alone is not sufficient to accurately predict DUI. As a result, there is growing interest in identifying other types of individual differences that might predict this behavior better, such as attitudinal variables. The aim of this study was to examine differences in personality dimensions and attitudes between a group of DUI offenders and a comparison group. Ninety-eight subjects were assessed: 51 subjects who had been convicted of a DUI offense following a diversion program, and 47 drivers without criminal records. Personality was measured with the NEO-Five Factor Inventory (NEO-FFI) and antisocial attitudes were assessed with the Jesness InventoryRevised. Results indicated that offenders were more prone to show antisocial attitudes $(p<.001)$ than comparisons. In terms of personality, there were no significant differences between the two groups. These findings suggest that attitudes may be useful predictors of DUI and should be taken into account in interventions designed to avoid recidivism.
\end{abstract}

(c) 2012 Elsevier Ltd. All rights reserved.

\section{Introduction}

In recent years, many countries have developed policies based on speed control, as well as alcohol and drug roadside tests in order to reduce traffic accidents. A large proportion of crimes against traffic safety are still related to driving under the influence (DUI) of alcohol and other intoxicants; according to the Commission of the European Communities (2006) report approximately one accident in four in the EU can be linked to alcohol consumption. The terminology and the thresholds used to determine DUI offenses vary across countries, but still constitutes a serious problem as previous DUI offenses increase the likelihood of later recidivism (Ahlin et al., 2011; Cavaiola et al., 2007; Hubicka et al., 2010; Portman et al., 2010). Hence, DUI offenses have been identified as a key target in prevention and intervention for road traffic safety.

\subsection{Personality and risky driving}

Previous research on this topic has shown that individual differences in terms of personality traits may be useful to predict risky driving. Personality can be defined as a unique pattern of cognitions, emotions and behaviors which are relatively stable in time and across situations. Within the framework of the five-factor

\footnotetext{
* Corresponding author at: Faculty of Psychology, University of Barcelona, P. Vall d'Hebron, 171, 08035 Barcelona, Spain. Tel.: +34 933125865; fax: +34 934021362. E-mail address: david.gallardo@ub.edu (D. Gallardo-Pujol).
}

model of personality (FFM) (Costa and McCrae, 1992), neuroticism has been positively correlated to risky driving and road accidents (Matthews et al., 1991) and aggressive driving and driving anger (Dahlen and White, 2006; Jovanović et al., 2011), but negatively correlated to convictions due to traffic offending (Furnham and Saipe, 1993). Extraversion has been related to traffic accidents, traffic offending and DUI (Lajunen, 2001; Renner and Anderle, 2000).The relation between openness to experience and risky driving and DUI is unclear (Hubicka et al., 2010; Miles and Johnson, 2003). Agreeableness has also shown an inverse correlation to traffic citations (Cellar et al., 2000) and aggressive driving (Benfield et al., 2007), although other studies have not confirmed this association (Miles and Johnson, 2003). Finally, conscientiousness is negatively correlated with risky driving, accident involvement and DUI (Arthur and Doverspike, 2001; Arthur and Graziano, 1996; Hagger-Johnson and Whiteman, 2007; Hubicka et al., 2010).

Narrower personality traits, defined as those traits that are not explicitly included within a structural model of personality such as the Big Five, may also help to understand the relationship between personality and risky driving. Impulsivity has been extensively related to risky driving (Dahlen et al., 2005), but sensation-seeking is the trait that has shown the most consistent predictive power (Dahlen et al., 2005; Dahlen \& White, 2006; Fernandes et al., 2010, 2007; Iversen \& Rundmo, 2002). Other personality traits have also been related to risky driving. When examining the relationship between personality factors assessed during adolescence and persistent risky driving in young adulthood, Gulliver and Begg (2007) found that, after adjusting for driving exposure, high levels of 
aggressiveness and alienation predicted being a driver involved in a crash.

However, despite evidence of the relationship between personality and risky driving, certain authors have not been able to replicate the association and claim that this issue requires further investigation (Ames et al., 2002; Oltedal and Rundmo, 2006; Schell et al., 2006). Other researchers have proposed related constructs such as trait driving anger, which is defined as the propensity to become angry while driving (Dahlen et al., 2005; Dahlen and White, 2006; Iversen and Rundmo, 2002; Sullman et al., 2007). But in general, the predictive power of personality traits is quite limited, especially when controlling for confounding variables (Schell et al., 2006).

\subsection{Attitudes and risky driving}

Empirical research suggests that personality is not enough to explain DUI behavior (Schell et al., 2006). Therefore, interest in finding alternative explanatory variables has been growing, precisely due to the identification of attitudinal variables in the development and maintenance of risky driving behavior in longitudinal studies (Greenberg et al., 2005). Attitudes can be defined as overall evaluations of an object that can affect behavior and are open to change. That is why most researchers have focused on programs for changing attitudes toward DUI and perceptions of the likelihood of adverse consequences as a result of DUI, in order to promote deterrence and reduce recidivism. In fact, it has been shown that attitudes and beliefs toward risky driving and DUI play a key role in predicting recidivism (Chen, 2009; Greenberg et al., 2004, 2005; Iversen, 2004).

\subsection{Personality, attitudes and risky driving}

Surprisingly few studies have addressed the role of personality and attitudes together in relation to risky driving. Schell and colleagues explored the role of attitudes, behavior and personality variables in DUI (Schell et al., 2006). They found a near zero correlation between DUI and Impulsivity and Hostility when they controlled for socially desirable responding bias, and no relation at all between Sensation seeking and DUI when this relationship was adjusted for behavior factors such as drinking frequency and high risk driving style. However, attitudes toward alcohol consumption had an important effect on DUI recidivism after adjusting for personality differences. According to their findings, positive expectancies about alcohol, frequent drinking and low levels of social desirability were the strongest predictors of DUI. Ulleberg and Rundmo (2003) also found that the effect of personality on risky driving in young drivers was mediated by traffic safety attitudes.

To the best of our knowledge, the literature has focused on very specific attitudes toward DUI, but few studies have examined general attitudes toward antisocial behavior. In the present study, our aim is to explore the personality and attitudinal variables that are related to DUI. We hypothesize that (1) among personality traits, neuroticism and conscientiousness will be related to DUI, and (2) attitudes toward antisocial behavior will also be associated with DUI. More specifically, as exponents of a particular type of antisocial behavior, we expect DUI offenders to show higher levels of neuroticism and lower levels of conscientiousness (Ozer and BenetMartínez, 2006), along with higher levels of antisocial attitudes in general.

\section{Method}

\subsection{Participants}

The study sample consisted of 98 Caucasian men, with an average age of 33.70 years $(S D=10.22)$. Fifty-one participants were following a diversion program after a DUI offense, and 47 were drivers without criminal records. These individuals were asked about misdemeanors in the last five years and then completed the questionnaires.

\subsection{Procedure}

DUI offenders were following a diversion program as a conviction for a DUI offense. They were asked to participate in the study voluntarily during the first session of the diversion program and completed the questionnaires in groups. They belonged to different groups and were admitted consecutively.

Comparison group was a convenience sample composed by drivers who were renewing their driver's license, and Criminology students from the Universitat de Barcelona assessed during a class session.

The study was conducted with the approval of the university's Research Ethics Board and the targeted institutions.

\subsection{Materials}

\subsubsection{NEO-FFI}

To assess personality, we used the Spanish adaptation of the NEO-Five Factor Inventory (NEO-FFI), based on the Five Factor Model (Costa and McCrae, 1992). The inventory comprises 60 items with a 5-point Likert-type response scale, measuring five dimensions: neuroticism $(N)$, extraversion $(E)$, openness $(O)$, agreeableness (A), and conscientiousness (C). Evidence for the reliability and validity of this Spanish adaptation of the NEO-FFI is reported in Aluja et al. (2005).

\subsubsection{Jesness Inventory-Revised}

Attitudes toward antisocial behavior were assessed with the Spanish version (Andrés-Pueyo and Antequera, 2006) of the Jesness Inventory-Revised (JI-R; Jesness, 1996), a 160-item, true/false self-report. This inventory measures 11 personality scales: social maladjustment (SM/SMx), value orientation (VO), immaturity $(\mathrm{Imm})$, autism $(\mathrm{Au})$, alienation $(\mathrm{Al})$, manifest aggression (MA), withdrawal-depression (Wd), social anxiety (SA), repression (Rep), and denial (Den); 9 attitudinal scales: undersocialized, active (unsocialized, aggressive) (AA); undersocialized, passive (unsocialized, passive) (AP); conformist (immature conformist) (CFM); group-oriented (cultural conformist) (CFC); pragmatist (manipulator) (MP); autonomy-oriented (neurotic, acting-out) (NA); introspective (neurotic, anxious) (NX); inhibited (situational) (SE); and adaptive (cultural identifier) (CI); and 2 subscales referring DSM-IV typologies: conduct disorder (CD), and oppositional defiant disorder (ODD). This questionnaire was originally designed to assess antisocial attitudes in adolescents, but has shown its utility with adults. Internal consistencies ranged from 0.61 to 0.93 , and a test-retest one-year term reliability ranged from 0.50 to 0.72 (Jesness, 1996).

\subsection{Statistical analysis}

First, we carried out a descriptive study of the variables to record the characteristics of the DUI and comparison groups. Then, since many attitudinal variables from the JI-R were highly correlated with each other, a principal component analysis (PCA) with oblimin direct rotation was carried out to obtain composite attitudinal scales. Third, a hierarchical logistic regression analysis was conducted in order to establish which personality and attitudinal 
variables were unique predictors of group assignment ${ }^{1}$. Age and educational level were introduced to adjust for their effect. Finally, receiver operating characteristic (ROC) analysis was conducted to explore the predictive validity of the measures.

The logistic regression model is used to fit a given set of data to the logistic function. The logistic function takes as an input any value from negative infinity to positive infinity, while the output only ranges from 0 to 1 . The variable $z$ represents a set of independent variables. The logistic function is expressed as follows:

$f(z)=\frac{1}{1+e^{-z}}$

where $e$ is the base of the natural logarithm and,

$z=\beta_{0}+\beta_{1} x_{1}+\beta_{2} x_{2}+\beta_{3} x_{3}+\cdots+\beta_{k} x_{k}$

We performed a hierarchical regression on three steps in order to test the incremental validity of each step. In the first one, we introduced the demographic data (age and education). In the second step, we entered the personality variables. Finally, in the third step, we introduced attitudinal information. Changes in Nagelkerke's pseudo- $R^{2}$ were used to assess incremental validity and model selection. We also assessed absolute fit of the model by means of the Homer-Lemeshow Chi-squared value.

With respect to the ROC analysis, we looked at sensitivity, specificity, optimal cut-off point and the area under the curve. Sensitivity and specificity are statistical measures of the performance of binary classification tests, in the present study, the logistic regression. On the one hand, sensitivity (SE) can be defined as the proportion of true positives that are correctly classified as such by the prediction model.

sensitivity $=\frac{\text { true positives }}{\text { true positives }+ \text { false negatives }}$

On the other hand, specificity (SP) is the proportion of true negatives that are classified as such among those who are classified as negatives by the prediction model.

specificity $=\frac{\text { true negatives }}{\text { true negatives }+ \text { false positives }}$

With regard to the optimal cut-off point, it is determined by the Youden's index $J$, which returns the maximum value of the expression:

$j=\max \left(S E_{t}+S P_{t}-1\right)$

where $S E_{t}$ and $S P_{t}$ represent sensitivity and specificity over all possible thresholds $(t)$. Area Under Curve (AUC) is the probability that the prediction model will rank a randomly selected positive case higher than a randomly selected negative case.

\section{Results}

Table 1 shows descriptive statistics for the variables by group. Differences were found in educational level between the DUI group and the comparison group: whereas $89 \%$ of comparison group subjects had completed higher education, only $38.3 \%$ of the DUI offenders had reached a level higher than primary school ( $\left.\chi^{2}=71.25, \mathrm{df}=2, p<.001\right)$. In terms of personality, no significant differences were found between both groups.

\footnotetext{
${ }^{1}$ We also fitted a mixed-effects model, in which we treated education as a fixed effect and age, personality and attitudes as random effects. Results from these analyses were unable to detect neither significant random intercepts, nor random slopes, suggesting that this type of analysis does not contribute significantly to the interpretation of our data.
}

Table 1

Descriptive statistics by group.

\begin{tabular}{|c|c|c|c|c|c|}
\hline \multirow[t]{2}{*}{ Scale } & \multicolumn{2}{|c|}{ DUI offenders $N=51$} & \multicolumn{2}{|c|}{ Comparisons $N=47$} & \multirow[t]{2}{*}{$t$-test } \\
\hline & Mean & SD & Mean & SD & \\
\hline Age & 36.96 & 9.52 & 30.57 & 9.98 & $-3.14^{*}$ \\
\hline \multicolumn{6}{|l|}{ Education } \\
\hline Primary & $61.7^{\mathrm{a}}$ & & $8.7^{\mathrm{a}}$ & & \\
\hline Secondary & $36.2^{\mathrm{a}}$ & & $2.2^{\mathrm{a}}$ & & \\
\hline High & $2.1^{\mathrm{a}}$ & & $89.1^{\mathrm{a}}$ & & \\
\hline \multicolumn{6}{|l|}{ NEO-FFI } \\
\hline $\mathrm{N}$ & 32.62 & 6.54 & 32.00 & 4.50 & -.54 \\
\hline $\mathrm{E}$ & 36.50 & 5.78 & 37.72 & 2.95 & 1.32 \\
\hline $\mathrm{O}$ & 35.36 & 6.31 & 35.74 & 3.99 & .36 \\
\hline A & 34.86 & 5.70 & 37.38 & 3.65 & 2.58 \\
\hline C & 39.60 & 7.43 & 42.19 & 3.21 & 2.25 \\
\hline \multicolumn{6}{|c|}{ Jesness Inventory Revised } \\
\hline SM & 25.57 & 14.73 & 12.32 & 6.91 & $-5.77^{*}$ \\
\hline vo & 15.06 & 10.28 & 6.83 & 5.23 & $-5.05^{*}$ \\
\hline $\mathrm{Imm}$ & 12.84 & 5.63 & 7.91 & 4.54 & $-4.79^{*}$ \\
\hline $\mathrm{Au}$ & 10.69 & 6.97 & 5.87 & 3.44 & $-4.39^{*}$ \\
\hline $\mathrm{Al}$ & 10.61 & 5.91 & 5.00 & 3.38 & $-5.82^{*}$ \\
\hline MA & 13.38 & 6.85 & 7.26 & 6.27 & $-4.52^{*}$ \\
\hline Wd & 10.88 & 2.97 & 7.85 & 2.50 & $-5.44^{*}$ \\
\hline SA & 9.27 & 3.03 & 7.98 & 4.50 & -1.66 \\
\hline Rep & 6.20 & 2.75 & 5.40 & 2.27 & -1.55 \\
\hline Den & 11.88 & 7.46 & 14.68 & 3.16 & 2.45 \\
\hline SMx & 11.47 & 7.79 & 3.77 & 3.32 & $-6.46^{*}$ \\
\hline $\mathrm{AA}$ & 23.92 & 16.31 & 9.98 & 9.73 & $-5.18^{*}$ \\
\hline $\mathrm{AP}$ & 22.37 & 12.92 & 10.21 & 8.21 & $-5.61^{*}$ \\
\hline CFM & 25.98 & 13.47 & 30.13 & 4.97 & 2.05 \\
\hline CFC & 18.20 & 5.77 & 14.38 & 3.98 & $-3.83^{*}$ \\
\hline $\mathrm{MP}$ & 18.06 & 9.24 & 19.34 & 4.33 & .87 \\
\hline NA & 23.08 & 6.64 & 19.00 & 3.74 & $-3.78^{*}$ \\
\hline $\mathrm{NX}$ & 37.37 & 11.85 & 34.96 & 4.69 & -1.35 \\
\hline $\mathrm{SE}$ & 47.86 & 29.50 & 54.77 & 11.09 & 1.56 \\
\hline $\mathrm{CI}$ & 23.12 & 11.72 & 26.38 & 4.35 & 1.86 \\
\hline $\mathrm{CD}$ & 5.18 & 4.91 & 2.74 & 2.38 & $-3.16^{*}$ \\
\hline ODD & 7.20 & 3.03 & 5.38 & 3.03 & -2.96 \\
\hline Lie & 2.10 & 1.33 & 1.45 & .88 & -2.88 \\
\hline
\end{tabular}

Note: $\mathrm{N}=$ neuroticism; $\mathrm{E}=$ extraversion; $\mathrm{O}=$ openness $\quad$ to experience;
$\mathrm{A}=$ agreeableness; $\mathrm{C}=$ conscientiousness; $\mathrm{SM}=$ social maladjustment; $\mathrm{VO}=$ value orientation; $\mathrm{Imm}=$ immaturity; $\mathrm{Au}=$ autism; $\mathrm{Al}=$ alienation; $\mathrm{MA}=$ manifest aggression; $\mathrm{Wd}=$ withdrawal-depression; $\mathrm{SA}=$ social anxiety; $\mathrm{Rep}=$ repression; Den =denial; $\mathrm{SMx}=\mathrm{SMx} ; \quad \mathrm{AA}=$ under-socialized active; $\mathrm{AP}=$ under-socialized passive; $\mathrm{CFM}=$ conformist; $\mathrm{CFC}=$ group-oriented; $\mathrm{MP}=$ pragmatist; $\mathrm{NA}=$ autonomy oriented; $\mathrm{NX}=$ introspective; $\mathrm{SE}=$ inhibited; $\mathrm{CI}=$ adaptive; $\mathrm{CD}=$ conduct disorder; ODD = oppositional defiant disorder; Lie $=$ lie scale.

a This number expresses the percentage of people within groups.

$p$ significant after Bonferroni's correction.

In the correlation matrix between personality and attitudinal variables, the attitudinal scales were highly associated with each other ${ }^{2}$. Thus, to avoid problems related to multicollinearity between the JI-R attitudinal variables a principal components analysis was performed. We extracted the components based on Cattell's scree test and Eigenvalue greater than one criterion. The results suggested that three components should be retained, which were labeled antisocial attitudes, emotional stability and honesty. Factor loadings of the attitudinal scales, which accounted for $85 \%$ of the total variance, are shown in Table 2.

Table 3 shows the correlations between new composite attitudinal scales. As expected, no significant correlations between components were found.

Then, a logistic regression analysis was conducted using personality variables and composite attitudinal scores to predict group assignment (DUI offender or comparison group). The results (Table 4) showed a significant prediction of group assignment using these personality and attitudinal variables $\left(\chi^{2}=91.44, \mathrm{df}=10\right.$, $p<.001$ ), and the model was well fitted (Hosmer-Lemeshow

\footnotetext{
2 Correlation matrix is available upon request.
} 
Table 2

Principal component analysis of attitudinal variables with oblimin direct rotation.

\begin{tabular}{|c|c|c|c|}
\hline \multirow[t]{2}{*}{ Attitudinal scales } & \multicolumn{3}{|c|}{ Components } \\
\hline & 1 & 2 & 3 \\
\hline VO & .98 & -.11 & .29 \\
\hline $\mathrm{AA}$ & .97 & -.13 & .30 \\
\hline SE & -.97 & .14 & -.21 \\
\hline SM & .97 & -.06 & .34 \\
\hline AP & .96 & -.31 & .28 \\
\hline SMx & .95 & -.05 & .28 \\
\hline Imm & .93 & -.31 & .26 \\
\hline CFM & -.93 & .02 & -.06 \\
\hline MA & .93 & -.20 & .26 \\
\hline $\mathrm{Al}$ & .92 & -.09 & .21 \\
\hline $\mathrm{Au}$ & .92 & -.02 & .36 \\
\hline Den & -.91 & .34 & -.21 \\
\hline $\mathrm{CI}$ & -.90 & .06 & -.08 \\
\hline CFC & .86 & .12 & .23 \\
\hline $\mathrm{CD}$ & .86 & .04 & .31 \\
\hline ODD & .84 & -.16 & .03 \\
\hline Wd & .74 & -.47 & .00 \\
\hline MP & -.73 & .64 & -.09 \\
\hline NA & .69 & -.23 & -.18 \\
\hline NX & -.24 & -.85 & -.26 \\
\hline SA & .45 & -.80 & -.13 \\
\hline Rep & .16 & .18 & .94 \\
\hline Lie & .34 & .11 & .91 \\
\hline Exp. Var. & $68.40 \%$ & $10.60 \%$ & $6.15 \%$ \\
\hline
\end{tabular}

Note: Factor loadings >.65 are in boldface. Exp. Var.=percentage of variance explained. $1=$ antisocial attitudes; $2=$ emotional stability; $3=$ honesty $\mathrm{VO}=$ value orientation; $\mathrm{AA}=$ under-socialized active; $\mathrm{SE}=$ inhibited; $\mathrm{SM}=$ socia maladjustment; $\mathrm{AP}=$ under-socialized passive; $\mathrm{SMx}=\mathrm{SMx} ; \mathrm{Imm}=$ immaturity; $\mathrm{CFM}=$ conformist $; \quad \mathrm{MA}=$ manifest $\quad$ aggression; $\mathrm{Al}=$ alienation; $\mathrm{Au}=$ autism; Den $=$ denial $; \quad \mathrm{CI}=$ adaptive $\quad \quad \mathrm{CFC}=$ group-oriented $; \quad \mathrm{CD}=$ conduct $\quad$ disor der; $\quad$ ODD = oppositional defiant disorder; $\mathrm{Wd}=$ withdrawal-depression; $\mathrm{MP}=$ pragmatist; $\mathrm{NA}=$ autonomy oriented; $\mathrm{NX}=$ introspective; $\mathrm{SA}=$ social anxiety; Rep $=$ repression; Lie $=$ lie scale

Table 3

Correlation matrix between components.

\begin{tabular}{lrrr}
\hline Components & 1 & 2 & 3 \\
\hline 1 & 1.00 & & \\
2 & -.15 & 1.00 & \\
3 & .20 & .15 & 1.00
\end{tabular}

Note: 1 = antisocial attitudes; 2 = emotional stability; 3 = honesty.

$\left.\chi^{2}=3.72, \mathrm{df}=8, p=.88\right)$, explaining a considerable amount of variance $\left(R^{2}\right.$ Nagelkerke $\left.=0.86\right)$. Education $(\mathrm{OR}=0.01)$, neuroticism $(\mathrm{OR}=1.53)$, conscientiousness $(\mathrm{OR}=0.46)$, and the attitudinal component labeled as antisocial attitudes $(\mathrm{OR}=8.23)$ were significant predictors of group assignment. According to the general logistic regression model, after fitting our data to this model, we obtained the following regression equation:

\section{$z=27.4+(-5.23)$ education +.42 neuroticism \\ $+(-.78)$ conscientiousness +2.11 antisocial_attitudes}

Hence, the function that we fitted in this study is:

\section{Discussion}

The aim of this study was to explore which personality and attitudinal variables were associated with DUI. Our findings bear out our hypotheses that certain personality and attitudinal characteristics may play an important role in the explanation of DUI. In particular, higher levels of neuroticism and lower levels of conscientiousness, and antisocial attitudes were related with DUI offenses.

Neuroticism emerged as a significant predictor of group assignment when we controlled for antisocial attitudes, although there was no significant difference in the scores between both groups. Many authors have also found a positive relation between neuroticism and aggressive driving, as a particular risky driving behavior. With regard to criminality, Ozer and Benet-Martínez (2006) reported a positive relation between neuroticism and antisocial behavior in general.

Conscientiousness was also found to be a good predictor of group assignment, and negatively related to DUI. Some authors have also reported the importance of conscientiousness in distinguishing between DUI offenders and the normal population (Hubicka et al., 2010), but no relation was found between this personality trait and other unsafe driving behaviors (Dahlen and White, 2006). Ozer and Benet-Martínez (2006) reported a negative relation between conscientiousness and antisocial behavior in general and criminal behavior.

As regards attitudes, significant differences were found between the two groups in most of the Jesness Inventory Scales, indicating that DUI offenders show more antisocial attitudes than the comparison group. So far, specific sets of driving related attitudes have been identified (Iversen and Rundmo, 2002; Miles and Johnson, 2003; Ulleberg and Rundmo, 2003; Yilmaz and Çelik, 2008), but as yet no study has identified general antisocial attitudes as predictors of DUI. On this basis, the results from the ROC analysis showed personality and attitudes to be good predictors of DUI offending; the AUC $=.85$ suggests that personality and antisocial attitudes are good indicators of group assignment. These results support research by Begg et al. (2003), Fernandes et al. (2007) and Shinar et al. (2001) who concluded that DUI offending is a particular risky driving behavior, predicted by specific variables different from those related with other types of risky driving. In this sense, our results suggest that DUI offending is more similar in terms of personality and attitudes to general antisocial behavior (Andrews and Bonta, 2010; Ozer and Benet-Martínez, 2006) than to other unsafe driving behaviors.

In clinical terms, DUI offenders share personality characteristics with users and abusers of alcohol and other intoxicants, and with patients with alcohol-related problems (Ibáñez et al., 2010; Mezquita et al., 2010). Further investigation is needed in this field to understand DUI offending in terms of alcohol-related pathologies.

A comprehensive approach to DUI offenders should take into account these results to develop and improve targeted intervention programs focused on individuals with alcohol related problems, high neuroticism, low conscientiousness, and heavy antisocial attitudes. Although further investigation is needed in this field in order to explore the degree in which personality and antisocial attitudes influence the decision of driving under the influence of

$\mathrm{DUI}=\frac{1}{(1+\hat{e}(-(27.4+(-5.23) \text { education }+.42 \text { neuroticism }+(-7.8) \text { conscientiousness }+2.11 \text { antisocial_attitudes })))}$

Finally, receiver operating characteristic (ROC) analysis was conducted to explore the predictive capacity of the measures. The optimal cut-off point was 0.39 which gives a good sensitivity $(0.78)$ and specificity (0.79), with an area under the ROC curve (AUC) of 0.85 . alcohol, these variables should be taken into account in intervention programs focused on DUI offending in order to improve the effectiveness of the treatment. These variables should also be taken 
Table 4

Hierarchical logistic regression from the prediction of group status.

\begin{tabular}{|c|c|c|c|c|c|c|}
\hline & $R^{2}$ Nagelkerke & $-2 \log$ likelihood & Wald & Sig & $\operatorname{Exp}(B)$ & CI $95 \%$ for $\operatorname{Exp}(B)$ \\
\hline Step 1 & .71 & 55.01 & & & & \\
\hline Age & & & 1.26 & .26 & .95 & {$[.87 ; 1.04]$} \\
\hline Education & & & 22.97 & $<.01$ & .05 & {$[.01 ; .16]$} \\
\hline Step 2 & .79 & 43.67 & & & & \\
\hline Age & & & 2.77 & .10 & .91 & {$[.82 ; 1.02]$} \\
\hline Education & & & 18.44 & $<.01$ & .02 & {$[.00 ; .11]$} \\
\hline $\mathrm{N}$ & & & .85 & .36 & 1.08 & {$[.91 ; 1.28]$} \\
\hline $\mathrm{E}$ & & & 2.10 & .15 & 1.19 & {$[.94 ; 1.52]$} \\
\hline $\mathrm{O}$ & & & .04 & .84 & .98 & {$[.80 ; 1.20]$} \\
\hline A & & & .32 & .57 & .95 & {$[.79 ; 1.14]$} \\
\hline C & & & 5.99 & .01 & .69 & {$[.52 ; .93]$} \\
\hline Step 3 & .86 & 30.37 & & & & \\
\hline Age & & & .85 & .36 & .93 & {$[.79 ; 1.09]$} \\
\hline Education & & & 9.00 & $<.01$ & .01 & {$[.00 ; .16]$} \\
\hline $\mathrm{N}$ & & & 3.85 & .05 & 1.53 & {$[1.00 ; 2.33]$} \\
\hline $\mathrm{E}$ & & & 1.67 & .20 & 1.23 & {$[.90 ; 1.70]$} \\
\hline $\mathrm{O}$ & & & .63 & .43 & .90 & {$[.69 ; 1.17]$} \\
\hline A & & & .02 & .88 & 1.02 & {$[.80 ; 1.30]$} \\
\hline $\mathrm{C}$ & & & 5.57 & .02 & .46 & {$[.24 ; .88]$} \\
\hline Component 1 & & & 6.19 & .01 & 8.23 & {$[1.56 ; 43.28]$} \\
\hline Component 2 & & & 2.37 & .12 & 2.71 & {$[.76 ; 9.66]$} \\
\hline Component 3 & & & 2.76 & .10 & 5.80 & {$[.73 ; 46.20]$} \\
\hline
\end{tabular}

Note: $n=98 . \mathrm{N}=$ neuroticism; $\mathrm{E}=$ extraversion; $\mathrm{O}=$ openness to experience; $\mathrm{A}=$ agreeableness; $\mathrm{C}=$ conscientiousness; Component $1=$ antisocial attitudes; Component 2 = emotional stability; Component 3 = honesty.

into consideration as a screening procedure when designing training programs for teen drivers, so that the program could be created according to the characteristics of each type of drivers, predicting which drivers are at risk of driving under the influence of alcohol and, so, to be able to intervene in advance. Moreover, as attitudes can change due to experience, prevention and intervention, they seem to be a good target and outcome measure for intervention programs (Jewell et al., 2008; McCarthy et al., 2006). Additionally, as personality predicts adherence to intervention programs, it should be taken into account in order to promote criminal deterrence (Harkness \& Lilienfeld, 1997).

Among the limitations of our study we should mention the sample characteristics. Given the exploratory nature of this study, our sample size was small and as the comparison group is a convenience sample, the range of educational levels was substantially different. Although we controlled for the educational level in the analysis, it may have influenced the results in an unknown direction. However, higher education samples do not differ from the general population in terms of general offending (Wiecko, 2010). Another limitation is the fact that all the DUI offenders were following a diversion program, and of course not all DUI offenders fit this profile. Future work should explore a broader sample of DUI offenders to compare different profiles and to determine common characteristics in order to generalize the findings of this study to the treatment of other traffic offenders. Other caveats include the low incidence of DUI among women (Portman et al., 2010). In this sense, during the data-gathering phase, any woman took part in the diversion programs where the participants come from. This could result in gender-biased interpretation. Hence, we would like to point out that the conclusions drawn from the present study do only apply to men. Choices on data analysis strategy can also affect the results and their interpretation. For instance, logistic regression tends to overestimate the parameters of the model when sample size is under 500 , although the standard error is no seriously affected (Nemes et al., 2009). The last limitation we should mention is the choice of instruments used. As the literacy skills of the DUI offender sample may be limited, this possible shortcoming may have interfered in some way in the results, although we used a short version of the questionnaire to assess personality. As for the NEO-FFI, it provides information about the five general dimensions of personality but not about the facets, and some subtle aspects of personality may have been missed. With respect to the Jesness Inventory-Revised, although its utility to assess antisocial attitudes in adults has been proved, in our analysis we used new composite scales derived from a principal components analysis. This may have hampered our ability to detect the effects of attitudes on DUI, and therefore these results have to be regarded carefully.

To conclude, there are individual and psychosocial variables that discriminate between DUI offenders and people without criminal records. DUI offenses represent a particular type of unsafe driving that seems to share more characteristics with antisocial behavior and delinquency than with specific traffic violations (Ozer \& BenetMartínez, 2006; Rodríguez-Fornells et al., 2002).

\section{Acknowledgements}

This research was supported in part by the PSI2009-07726 and PSI2009-13265 grants, both from the Spanish Ministry of Science. The authors would like to acknowledge the Ministry of Justice of the Government of Catalonia and all who volunteered to participate in this study.

\section{References}

Ahlin, E.M., Zador, P.L., Rauch, W.J., Howard, J.M., Duncan, G.D., 2011. First-time DWI offenders are at risk of recidivating regardless of sanctions imposed. Journal of Criminal Justice 39 (2), 137-142.

Aluja, A., García, O., Rossier, J., García, L.F., 2005. Comparison of the NEO-FFI, the NEO-FFI-R and an alternative short version of the NEO-PI-R (NEO-60) in Swiss and Spanish samples. Personality and Individual Differences 38 (3), 591-604.

Ames, S.L., Zogg, J.B., Stacy, A.W., 2002. Implicit cognition, sensation seeking, marijuana use and driving behavior among drug offenders. Personality and Individual Differences 33 (7), 1055-1072.

Andrés-Pueyo, A., Antequera, M., 2006. Adaptación española del Jesness Inventory Revised [Spanish Adaptation of the Jesness Inventory revised]. Unpublished manuscript, Universitat de Barcelona, Barcelona, Spain.

Andrews, D.A., Bonta, J., 2010. The Psychology of Criminal Conduct, 5th ed. Mathew Bender \& Co./Lexis Nexis Group, New Providence, NJ.

Arthur, W., Doverspike, D., 2001. Predicting motor vehicle crash involvement from a personality measure and a driving knowledge test. Journal of Prevention \& Intervention in the Community 22 (1), 35-42.

Arthur, W., Graziano, W.G., 1996. The five-factor model, conscientiousness, and driving accident involvement. Journal of Personality 64 (3), 593-618.

Begg, D.J., Langley, J.D., Stephenson, S., 2003. Identifying factors that predict persistent driving after drinking, unsafe driving after drinking, and driving after using cannabis among young adults. Accident Analysis \& Prevention 35 (5), 669-675. 
Benfield, J.A., Szlemko, W.J., Bell, P.A., 2007. Driver personality and anthropomorphic attributions of vehicle personality relate to reported aggressive driving tendencies. Personality and Individual Differences 42 (2), 247-258.

Cavaiola, A.A., Strohmetz, D.B., Abreo, S.D., 2007. Characteristics of DUI recidivists: a 12-year follow-up study of first time DUI offenders. Addictive Behaviors 32 (4) $855-861$.

Cellar, D.F., Nelson, Z.C., Yorke, C.M., 2000. The five-factor model and driving behavior: personality and involvement in vehicular accidents. Psychological Reports $86(2), 454-456$.

Commission of the European Communities, 2006. Communication from the Commission to the Council, the European Parliament, the European Economic and Social Committee and the Committee of the Regions: An EU strategy to support Member States in reducing alcohol related harm. Retrieved from http://eurlex.europa.eu/smartapi/cgi/sga_doc?smartapi!celexplus! prod!DocNumber\&lg $=$ en\&type_doc=COMfinal\&an_doc $=2006 \&$ nu_doc $=625$.

Costa, P.T., McCrae, R.R., 1992. Revised NEO Personality Inventory (NEO-PI-R) and the NEO Five-Factor Inventory (NEO-FFI) Professional Manual. Psychological Assessment Resources, Odessa, FL.

Chen, C.-F., 2009. Personality, safety attitudes and risky driving behaviors-evidence from young Taiwanese motorcyclists. Accident Analysis \& Prevention 41 (5), 963-968, http://dx.doi.org/10.1016/j.aap.2009.05.013.

Dahlen, E.R., Martin, R.C., Ragan, K., Kuhlman, M.M., 2005. Driving anger, sensation seeking, impulsiveness, and boredom proneness in the prediction of unsafe driving. Accident Analysis \& Prevention 37 (2), 341-348.

Dahlen, E.R., White, R.P., 2006. The Big Five factors, sensation seeking, and driving anger in the prediction of unsafe driving. Personality and Individual Differences 41 (5), 903-915, http://dx.doi.org/10.1016/j.paid.2006.03.016.

Fernandes, R., Hatfield, J., Soames Job, R.F., 2010. A systematic investigation of the differential predictors for speeding, drink-driving, driving while fatigued, and not wearing a seat belt, among young drivers. Transportation Research Part F: Traffic Psychology and Behaviour 13 (3), 179-196.

Fernandes, R., Job, R.F.S., Hatfield, J., 2007. A challenge to the assumed generalizability of prediction and countermeasure for risky driving: different factors predict different risky driving behaviors. Journal of Safety Research 38 (1), 59-70.

Furnham, A., Saipe, J., 1993. Personality correlates of convicted drivers. Personality and Individual Differences 14 (2), 329-336.

Greenberg, M.D., Morral, A.R., Jain, A.K., 2004. How can repeat drunk drivers be influenced to change? Analysis of the association between drunk driving and DU recidivists' attitudes and beliefs. Journal of Studies on Alcohol 65 (4), 460-463.

Greenberg, M.D., Morral, A.R., Jain, A.K., 2005. Drink-driving and DUI recidivists' attitudes and beliefs: a longitudinal analysis. Journal of Studies on Alcohol 66 (5), 640-647.

Gulliver, P., Begg, D., 2007. Personality factors as predictors of persistent risky driving behavior and crash involvement among young adults. Injury Prevention 13 (6), 376-381.

Hagger-Johnson, G.E., Whiteman, M.C., 2007. Conscientiousness facets and health behaviors: a latent variable modeling approach. Personality and Individual Differences 43 (5), 1235-1245.

Harkness, A.R., Lilienfeld, S.O., 1997. Individual differences science for treatment planning: personality traits. Psychological Assessment 9 (4), 349-360.

Hubicka, B., Källmén, H., Hiltunen, A., Bergman, H., 2010. Personality traits and mental health of severe drunk drivers in Sweden. Social Psychiatry and Psychiatric Epidemiology 45 (7), 723-731.

Ibáñez, M.I., Moya, J., Villa, H., Mezquita, L., Ruipérez, M.Á., Ortet, G., 2010. Basic personality dimensions and alcohol consumption in young adults. Personality and Individual Differences 48 (2), 171-176.

Iversen, H., 2004. Risk-taking attitudes and risky driving behaviour. Transportation Research Part F: Traffic Psychology and Behaviour 7 (3), 135-150, http://dx.doi.org/10.1016/j.trf.2003.11.003.

Iversen, H., Rundmo, T., 2002. Personality, risky driving and accident involvement among Norwegian drivers. Personality and Individual Differences 33 (8) 1251-1263, http://dx.doi.org/10.1016/S0191-8869(02)00010-7.
Jesness, C.F., 1996. The Jesness Inventory, 2nd ed. Multi-Health Systems, North Tonawanda, NY.

Jewell, J.D., Hupp, S.D.A., Segrist, D.J., 2008. Assessing DUI risk: Examination of the Behaviors \& Attitudes Drinking \& Driving Scale (BADDS). Addictive Behaviors 33 (7), 853-865

Jovanović, D., Lipovac, K., Stanojević, P., Stanojević, D., 2011. The effects of personality traits on driving-related anger and aggressive behaviour in traffic among Serbian drivers. Transportation Research Part F: Traffic Psychology and Behaviour 14 (1), 43-53.

Lajunen, T., 2001. Personality and accident liability: Are extraversion, neuroticism and psychoticism related to traffic and occupational fatalities? Personality and Individual Differences 31 (8), 1365-1373, doi:10.1016/S0191-8869(00)002300 .

Matthews, G., Dorn, L., Glendon, A.I., 1991. Personality correlates of driver stress. Personality and Individual Differences 12 (6), 535-549.

McCarthy, D.M., Pedersen, S.L., Thompsen, D.M., Leuty, M.E., 2006. Development of a measure of drinking and driving expectancies for youth. Psychological Assessment 18 (2), 155-164, http://dx.doi.org/10.1037/1040-3590.18.2.155.

Mezquita, L., Stewart, S.H., Ruipérez, M.Á., 2010. Big-five personality domains predict internal drinking motives in young adults. Personality and Individual Differences 49 (3), 240-245.

Miles, D.E., Johnson, G.L., 2003. Aggressive driving behaviors: are there psychological and attitudinal predictors? Transportation Research Part F: Traffic Psychology and Behaviour 6 (2), 147-161, http://dx.doi.org/10.1016/S13698478(03)00022-6.

Nemes, S., Jonasson, J.M., Genell, A., Steineck, G., 2009. Bias in odds ratio by logistic regression modelling and sample size. BMC Medical Research Methodology 9 (56).

Oltedal, S., Rundmo, T., 2006. The effects of personality and gender on risky driving behaviour and accident involvement. Safety Science 44 (7), 621-628.

Ozer, D.J., Benet-Martínez, V., 2006. Personality and the prediction of consequentia outcomes. Annual Review of Psychology 57, 401-421.

Portman, M., Penttilä, A., Haukka, J., Eriksson, P., Alho, H., Kuoppasalmi, K., 2010. Predicting DUI recidivism of male drunken driving: a prospective study of the impact of alcohol markers and previous drunken driving. Drug and Alcohol Dependence 106 (2-3), 186-192.

Renner, W., Anderle, F.-G., 2000. Venturesomeness and extraversion as correlates of juvenile drivers' traffic violations. Accident Analysis \& Prevention 32 (5), 673-678.

Rodríguez-Fornells, A., López-Capdevila, J.M., Andrés-Pueyo, A., 2002. Personalidad y comportamiento penitenciario [Personality and prison behavior]. Psicothema $14,90-100$.

Schell, T.L., Chan, K.S., Morral, A.R., 2006. Predicting DUI recidivism: personality, attitudinal, and behavioral risk factors. Drug and Alcohol Dependence 82 (1), 33-40.

Shinar, D., Schechtman, E., Compton, R., 2001. Self-reports of safe driving behaviors in relationship to sex, age, education and income in the US adult driving population. Accident Analysis \& Prevention 33 (1), 111-116.

Sullman, M.J.M., Gras, M.E., Cunill, M., Planes, M., Font-Mayolas, S., 2007. Driving anger in Spain. Personality and Individual Differences 42 (4), 701-713, http://dx.doi.org/10.1016/j.paid.2006.08.014.

Ulleberg, P., Rundmo, T., 2003. Personality, attitudes and risk perception as predictors of risky driving behaviour among young drivers. Safety Science 41 (5), 427-443, http://dx.doi.org/10.1016/S0925-7535(01)00077-7.

Wiecko, F.M., 2010. Research note: assessing the validity of college samples: Are students really that different? Journal of Criminal Justice 38 (6), 1186-1190, http://dx.doi.org/10.1016/j.jcrimjus.2010.09.007.

Yilmaz, V., Çelik, H.E., 2008. A model for explanation of personal attitudes toward traffic of candidate drivers attending drivers' courses: Risky candidate driver's attitude model. Transportation Research Part F: Traffic Psychology and Behaviour 11 (4), 233-241, doi:10.1016/j.trf.2007.10.003. 